\title{
Ether lipid vesicle-based antigens impart protection against experimental listeriosis
}

This article was published in the following Dove Press journal:

International Journal of Nanomedicine

27 May 2012

Number of times this article has been viewed

\section{Mairaj Ahmed Ansari' \\ Swaleha Zubair ${ }^{2}$ \\ Saba Tufail' \\ Ejaj Ahmad' \\ Mohsin Raza Khan' \\ Zainuddin Quadri' \\ Mohammad Owais'}

'Interdisciplinary Biotechnology Unit, ${ }^{2}$ Women's College, Aligarh Muslim

University, Aligarh, UP, India
Correspondence: Mohammad Owais Interdisciplinary Biotechnology Unit, Aligarh Muslim University, Aligarh, UP, India

Tel +9| 57| 2720388

Fax +91 57I 2721776

Email owais_lakhnawi@yahoo.com
Background: Incidence of food-borne infections from Listeria monocytogenes, a parasite that has adapted intracellular residence to avoid antibody onslaught, has increased dramatically in the past few years. The apparent lack of an effective vaccine that is capable of evoking the desired cytotoxic $\mathrm{T}$ cell response to obliterate this intracellular pathogen has encouraged the investigation of alternate prophylactic strategies. It should also be noted that Archaebacteria (Archae) lipid-based adjuvants enhance the efficacy of subunit vaccines. In the present study, the adjuvant properties of archaeosomes (liposomes prepared from total polar lipids of archaebacteria, Halobacterium salinarum) combined with immunogenic culture supernatant antigens of L. monocytogenes have been exploited in designing a vaccine candidate against experimental listeriosis in murine model.

Methods: Archaeosome-entrapped secretory protein antigens (SAgs) of L. monocytogenes were evaluated for their immunological responses and tendency to deplete bacterial burden in $\mathrm{BALB} / \mathrm{c}$ mice challenged with sublethal listerial infection. Various immunological studies involving cytokine profiling, lymphocyte proliferation assay, detection of various surface markers (by flowcytometric analysis), and antibody isotypes (by enzyme-linked immunosorbent assay) were used for establishing the vaccine potential of archaeosome-entrapped secretory proteins.

Results: Immunization schedule involving archaeosome-encapsulated SAgs resulted in upregulation of Th1 cytokine production along with boosted memory in BALB/c mice. It also showed protective effect by reducing listerial burden in various vital organs (liver and spleen) of the infected mice. However, the soluble form of the antigens (SAgs) and their physical mixture with sham (empty) archaeosomes, besides showing feeble Th1 response, were unable to protect the animals against virulent listerial infection.

Conclusion: On the basis of the evidence provided by the current data, it is inferred that archaeosome-entrapped SAgs formulation not only enhances cytotoxic $\mathrm{T}$ cell response but also helps in the clearance of pathogens and thereby increases the survival of the immunized animals.

Keywords: archaeosome, culture supernatant, antigen-presenting cells, Th1 cytokines, co-stimulatory markers, lymphocyte proliferation, protection studies

\section{Introduction}

Listeria monocytogenes, a ubiquitously present intracellular food-borne pathogen, causes listeriosis, an infection characterized by gastroenteritis, meningitis, encephalitis in general, and which sometimes inflicts maternofetal infections in humans as well as in cattle. Among the various food-borne infections, listeriosis has the highest fatality rate $(25 \%-30 \%) .{ }^{1}$ L. monocytogenes is able to penetrate and survive within both professional phagocytes (macrophages) as well as nonprofessional phagocytes and opts for an intracellular life cycle exhibiting competency for cell-to-cell spread, ${ }^{2}$ including epithelial cells, ${ }^{3}$ fibroblasts, ${ }^{4}$ hepatocytes, ${ }^{5}$ endothelial cells, ${ }^{6}$ and various 
types of nerve cells. ${ }^{7}$ Listeria spp. have also been shown to be taken up by, and to survive within, dendritic cells (DCs). ${ }^{8}$ Intracellular habitat and rapid-spreading capability in various kinds of cells renders safety to L. monocytogenes from antibody onslaught, which thereby facilitates its survival in the host.

The intracellular mode of residence acquired by L. monocytogenes to defy antibody attack seems to work equally well against various available antilisterial drug regimens. The situation is further worsened by other complications such as multidrug resistance and drug-associated side effects. Hence, designing an effective prophylactic strategy to combat listerial infection has become an important challenge to overcome. However, vaccine development against intracellular pathogens has always been a difficult task as most of the existing vaccine strategies generally evoke humoral response in the host. A promising strategy against intracellular pathogens is immunization with live attenuated strains that retain the ability to replicate within host cells, allowing processing and presentation of pathogen-derived antigens mainly via the major histocompatibility complex (MHC)-I pathway. Unfortunately, the generation of attenuated variants that effectively stimulate protective immune responses but do not result in disease manifestation, especially in immunocompromised individuals, remains the major hurdle in the development of an effective vaccine against $L$. monocytogenes.

Particulate adjuvants enhance the efficacy of subunit antigens presumably by enhanced targeting to antigenpresenting cells (APCs), including macrophages and DCs. Several preparations (natural as well as synthetic substances) have been shown to possess adjuvant activities both in animal models as well as in human subjects. ${ }^{9-11}$ Archaeosomes are also thought to be attractive adjuvant candidates owing to their promising potential to promote both MHC class I and class II responses to entrapped antigens as well as their ability to upregulate expression of co-stimulatory molecules on the surface of $\mathrm{APCs}^{10}$ without any associated toxicity in experimental animals. ${ }^{11}$

Among the various factors contributing to L. monocytogenes virulence, secretory proteins play the central role in activation of the host's immune system. ${ }^{12}$ Sixteen secreted virulence effectors have been characterized to date; some of these are associated with cytoplasmic membrane or cell wall (ActA, LLO, InlA, InlB, InlC, InlH, Mpl, MurA, PlcA, PlcB, P60, and SvpA), and others are released in the extracellular environment (Fri, TcsA, and Sod). Because of their potential to activate the host's immune system, secretory proteins can be exploited as a candidate vaccine and their abundance in culture supernatant offers an easy and economic strategy when used in large-scale vaccine production.

In the present study, a formulation of self-adjuvanting archaeosomes with soluble supernatant antigens of L. monocytogenes entrapped within was developed and its potential in controlling L. monocytogenes infection in experimental animals was evaluated.

\section{Materials and methods Chemicals and reagents}

All the reagents used were of the highest purity available. The following: fluorochrome-labeled anti-mouse antibodies; fluorescein isothiocyanate-conjugated CD4 (GK 1.5) and CD8 (53.67); PerCP-conjugated CD62L (MEL-14); phycoerythrin-conjugated CD44 (IM7), CD80 (B7-1), and CD86 (GL1); and IgG2a (R35-95) isotype control were procured from eBiosciences (San Diego, CA). Immunoglobulin (Ig) G1, IgG2a isotypes (550487) and cytokines viz. IL-4, interferon- $\gamma$, IL-12 cytokine estimation kits were procured from BD OptEIA (Franklin Lakes, NJ). Tissue culture media (RPMI 1640), bovine serum albumin (BSA), antimycotic solution, and plasticwares were purchased from BD Biosciences (San Diego, CA). Fetal calf serum was procured from Sigma-Aldrich ${ }^{\circledR}$ (St Louis, MO).

\section{Animals}

Inbred female BALB/c mice (6-8 weeks old, $20 \pm 2 \mathrm{~g}$ ) were obtained from the animal house facility of Interdisciplinary Biotechnology Unit, AMU. The animals were acclimatized for 10 days under standard husbandry conditions at room temperature $\left(22^{\circ} \mathrm{C} \pm 3^{\circ} \mathrm{C}\right)$, relative humidity $(65 \% \pm 10 \%)$, and a 12-hour light/dark cycle. They were allowed free access to standard dry pellet diet and water ad libitum under strict hygienic conditions. Animals were anesthetized with ketamine $(100 \mathrm{mg} / \mathrm{kg}$ body weight) in combination with xylazine (5 $\mathrm{mg} / \mathrm{kg}$ body weight) intramuscularly prior to sacrifice. All the procedures used in the study were reviewed and approved by the Institutional Animal Ethics Committee (Reg No: 332/2001/CPCSEA) as per the recommendations of the Committee for the Purpose of Control and Supervision of Experiments on Animals (India).

\section{Bacterial culture}

L. monocytogenes (15313) was procured from ATCC (American Type Culture Collection, Manassas, VA). Bacteria were grown on brain heart infusion (BHI) broth (Sigma-Aldrich) overnight at $37^{\circ} \mathrm{C}$. The bacteria were enumerated using McFarland's standard method ( 0.5$)$ by taking 
the optical density $\left(\mathrm{OD}_{590}\right)\left(0.1 \mathrm{OD}_{590}=1.5 \times 10^{9}\right.$ colony forming units $[\mathrm{CFU}] / \mathrm{mL})$.

\section{Isolation and sodium dodecyl sulfate- polyacrylamide gel electrophoresis (SDS-PAGE) profile of secretory proteins}

The cells were cultured in Brain Heart Infusion (BHI) broth for 48 hours. Thereafter, the culture supernatant was collected by centrifugation at $10,000 \mathrm{~g}$ for 10 minutes followed by filtration through $0.22 \mu \mathrm{m}$ filters (Millipore, Billerica, MA). The secretory proteins were allowed to precipitate by overnight treatment of filtrate with $80 \%$ ammonium sulfate at $4{ }^{\circ} \mathrm{C}$. The precipitated protein (pellet) was collected after centrifugation at $10,000 \mathrm{~g}$ for 10 minutes and was resuspended in $40 \mathrm{mM}$ phosphate buffer supplemented with $150 \mathrm{mM}$ sodium chloride $(\mathrm{NaCl})$ to obtain protein solution. Further vigorous dialysis was done to remove any media content from secretory proteins, which were lyophilized and stored for further use. Remaining supernatant was considered to be SAgs-depleted media and used as control in pilot studies. Proteins were subjected to $10 \%$ SDS-PAGE and stained with Coomassie Brilliant Blue R-250 dye (Imperial Chemical Industries, London, UK).

\section{Western blot analysis}

For Western blot analysis, SAgs ( $30 \mu \mathrm{g})$ were resolved by electrophoresis on $10 \%$ sodium dodecyl sulfate-polyacrylamide gel and transferred onto nitrocellulose membrane. After blocking in 3\%-5\% BSA prepared in phosphate-buffered saline (PBS) with Tween (PBST), the membrane was washed three times with PBS containing Tween 20 and incubated for 2 hours at $37^{\circ} \mathrm{C}$ with antibodies raised in mice against SAgs. After incubation and stipulated washing steps, the membrane was incubated with horseradish peroxidase-conjugated rabbit-anti-mouse antibody $(1: 2000)$ for 1 hour at $37^{\circ} \mathrm{C}$. Finally, the membrane was treated with 3,3' diaminobenzidine tetrahydrochloride solution $(10 \mathrm{mg}$ dissolved in $6 \mathrm{~mL}$ water) to develop bands of immunogenic proteins.

\section{Preparation of archaeosomes and determination of entrapment efficiency}

Total polar lipids from Halobacterium salinarum were harvested using a slightly modified Bligh and Dyer method in our lab. ${ }^{13}$ Specifically, H. salinarum was grown on nutrient broth agar plates with extra $1 \mathrm{M} \mathrm{NaCl}$. The cells were harvested and washed with PBS twice, thereafter; they were dispersed in chloroform and methanol (2:1 v/v) mixture followed by brief sonication using a probe sonicator $\left(\right.$ Sonics $^{\circledR}$, Vibra-Cell ${ }^{\mathrm{TM}}$,
Sonics and Materials Inc, Newtown, CT). After overnight stirring, the mixture was filtered using a sintered funnel. One volume of $150 \mathrm{mM} \mathrm{NaCl}$ was added to five volumes of the filtrate, and mixture was allowed to separate in a separating funnel until two phases appeared; the lower organic phase was collected and evaporated under vacuum using a rotary evaporator (Heidolph Instruments GmbH and Co KG, Schwabach, Germany).

For archaeosome preparation, a thin dry lipid film was made in an acid clean glass test tube. The film was hydrated with normal saline followed by sonication in a bath sonicator for 1 hour under $\mathrm{N}_{2}$ atmosphere. Archaeosomes thus formed were mixed with an equal volume of stock solution containing $10 \mathrm{mg} / \mathrm{mL}$ secretory proteins. The mixture was flash frozen and thawed ( $4-5$ cycles) followed by lyophilization to get free flowing powder using a lyophilizer (Alpha 1-4; Christ, Osterode, Germany). The powder was resuspended in $0.1 \% \mathrm{NaCl}$ solution to obtain dry reconstituted vesicles. Unentrapped protein was separated by loading the archaeosome protein mixture onto a sepharose 6-B column; protein-bearing archaeosomes were collected in the void volume. Percent entrapment was determined by estimating the released protein after archaeosomal burst in the presence of $1 \%$ TritonX-100 ${ }^{\mathrm{TM}}$ (Sigma-Aldrich Co).

\section{Characterization of SAgs-bearing archaeosomes}

The size of the in-house prepared archaeosomes was determined using a nanosize analyzer (nanophox; Malvern Instruments Ltd, Worcestershire, UK). Scanning electron microscopy (SEM) using SEM 430 (Leo, Peabody, MA) was also used to characterize the size and surface morphology of the protein-loaded archaeosomes. For electron microscopic studies, a lyophilized preparation of SAgs-loaded archaeosomes was suspended in $20 \mathrm{mM}$ PBS of $\mathrm{pH}$ 7.4. A drop was mounted on clear glass stub, air dried, and coated with gold-palladium alloy using a sputter coater. An accelerating voltage of $29.34 \mathrm{kV}$ was used for SEM imaging.

\section{Interaction of calcein-bearing archaeosomes with macrophages}

Calcein $(1 \mathrm{mM})$ dissolved in $0.1 \mathrm{~N} \mathrm{NaOH}(\mathrm{pH} 7.4)$ was loaded into the archaeosomes following published procedure as standardized in our lab. ${ }^{14}$ The archaeosomal preparation of calcein was then loaded onto the sepharose 6-B column to remove unentrapped calcein; the fraction with the calceinbearing archaeosomes was collected, pooled together, and lyophilized. After lyophilization, the powdered preparation 
was resuspended in distilled water. Macrophages (J774A.1 cell line) suspended in $200 \mu \mathrm{L}$ of media (RPMI 1640; Sigma-Aldrich, Co) were poured on $22-\mathrm{mm}^{2}$ glass coverslips placed in $35-\mathrm{mm}$ dishes at $2.5 \times 10^{4}$ cells per coverslip. Cells were allowed to attach for 2 hours and after washing with RPMI 1640 media, the dishes were filled with media. Twenty-four hours after plating, the cells were treated with archaeosomeencapsulated calcein for 1 hour. The cells were then fixed on ice in $4 \%$ methanol-free formaldehyde solution in PBS $(\mathrm{pH}$ 7.4) for 25 minutes. Finally, the cells were visualized by confocal laser scanning microscopy (CLSM) 510 Meta (Carl Zeiss Micromalging GmbH, Jena, Thuringen, Germany).

\section{Mode and schedule of immunization}

All the groups were immunized subcutaneously in the lower abdominal region aseptically with $50 \mu \mathrm{g}$ of SAgs (various forms) in $100 \mu \mathrm{L}$ of vehicle per animal corresponding to the lipid concentration in the range of $2.0-2.5 \mathrm{mg} /$ injection. A booster was given 3 weeks after the first immunization with $25 \mu \mathrm{g}$ of the corresponding SAgs formulation. PBS and sham archaeosome-administered groups acted as controls.

\section{Collection of sera}

The blood was collected from mice by retro-orbital puncture after various time intervals in centrifuge tubes, then centrifuged at $1500 \mathrm{~g}$ for 10 minutes at $4^{\circ} \mathrm{C}$. Finally, the supernatant was collected and used for ELISA analysis.

\section{Determination of antigen-specific isotypes by ELISA}

Antigen-specific total IgGs and their isotypes were determined in the sera of the immunized mice. Briefly, a 96-well microtiter plate was incubated overnight with $100 \mu \mathrm{L}$ of antigen $(200 \mathrm{ng})$ in carbonate-bicarbonate buffer $(0.05 \mathrm{M}, \mathrm{pH} 9.6)$ at $4^{\circ} \mathrm{C}$. After the usual washing and blocking steps, the plate was finally incubated with $\log _{10}$ two dilutions of test and control sera at $37^{\circ} \mathrm{C}$ for 2 hours. After excessive washing of the plate, $100 \mu \mathrm{L}$ of (1:5000 dilution of stock) goat anti-mouse IgG1 as well as goat anti-mouse IgG2a antibodies were added to specific wells. The plate was further incubated at $37^{\circ} \mathrm{C}$ for 1 hour. Again after washing, $100 \mu \mathrm{L}$ of (1:5000 dilution of stock) horseradish peroxidase (HRP) conjugated rabbit anti-goat antibodies were added to each well and the plate was incubated at $37^{\circ} \mathrm{C}$ for 1 hour. The plate was washed again before adding $100 \mu \mathrm{L}$ of substrate solution (6 mg $o$-phenylenediamine [OPD] in $12 \mathrm{~mL}$ of substrate buffer with $5 \mu \mathrm{L}$ of $30 \% \mathrm{H}_{2} \mathrm{O}_{2}$ ) and was finally incubated at $37^{\circ} \mathrm{C}$ for 40 minutes. The reaction was terminated by the addition of $50 \mu \mathrm{L}$ of $7 \% \mathrm{H}_{2} \mathrm{SO}_{4}$. The absorbance was read at $490 \mathrm{~nm}$ with a microtiter plate reader (Bio-Rad Laboratories Inc, Hercules, CA).

\section{Measurement of the anti-listerial DTH response}

The animals were immunized with various vaccine preparations in their inguinal region. The delayed type hypersensitivity (DTH) response was assessed at various time points after injection of antigen-containing archaeosomes as well as other control formulations. The mice were footpad tested to determine their DTH reactions to SAgs. ${ }^{15}$ DTH reactions were elicited by the injection of SAgs $(50 \mu \mathrm{g})$ in the right footpad of each mouse and saline into the left footpad. The thickness of each footpad was measured just before and after 24 hours, 48 hours, and 72 hours post-injection of SAgs or saline using a digital gauge caliper (Aerospace and Engineering Tools Ltd, Bolton, UK). DTH reactions were evaluated by the increase in footpad thickness as determined by the following formula (right footpad at testing time - right footpad at 0 hours): (left footpad at testing time - left footpad at 0 hours).

\section{Splenocyte isolation and culture}

The immunized mice were sacrificed by cervical dislocation and their spleens were aseptically removed. The single cell suspension made with the help of frosted glass slides was centrifuged at $1400 \mathrm{~g}$ for 8 minutes under cool conditions. The pellet was suspended in $2 \mathrm{~mL}$ of lysis buffer for 2-3 minutes to achieve lysis of the red blood cells and further diluted with PBS (total volume 10-15 mL). The cell suspension was again centrifuged at $1400 \mathrm{~g}$ and the pellet was further washed twice with Hank's buffered salt solution (HBSS).

\section{Lymphocyte proliferation assay}

A lymphocyte proliferation assay was performed following the method as standardized in our lab. ${ }^{13}$ Briefly, lymphocytes from the spleens of various immunized groups were incubated in round-bottomed, 96-well plates $\left(2 \times 10^{5}\right.$ cells per well) in $200 \mu \mathrm{L}$ of RPMI 1640 medium with $10 \%$ fetal bovine serum and increasing concentrations (1-20 $\mu \mathrm{g} /$ well) of SAgs. Cells incubated with the medium alone (without antigens) were used as controls. After 48 hours, the cultures were pulsed with $0.5 \mu \mathrm{Ci}$ of $\left[{ }^{3} \mathrm{H}\right]$-thymidine. The plates were harvested after 16 hours onto glass-fiber filter mats by the use of TomTec-Harvester-96 (Tomtec, Hamden, CT). The incorporated radioactivity was measured using liquid scintillation spectroscopy (Wallac-1450 MicroBeta TriLux, Cleveland, $\mathrm{OH})$. 


\section{Determination of IFN- $\gamma$, IL-I2, and IL-4 by sandwich ELISA}

IFN- $\gamma$, IL-12, and IL-4 expression levels in the culture supernatant of the lymphocytes isolated from various immunized groups were determined using appropriate, specific, and biotinylated antibody pairs according to the manufacturer's protocols. Briefly, $50 \mu \mathrm{L}$ of the purified capture antibodies were adsorbed overnight on polystyrene microtiter plates at $4^{\circ} \mathrm{C}$ in pH 9.5 carbonate buffer. Plates were washed five times with PBST and blocked with 5\% skimmed milk. After the usual steps of washing, $50 \mu \mathrm{L}$ of the supernatant of 48 -hour cultured splenocytes was used for the detection of cytokines. After the stipulated incubation time, the plates were thoroughly washed and incubated with biotinylated polyclonal goat anti-mouse IFN- $\gamma$, IL-12, and IL-4 antibodies. Afterwards, plates were washed thrice with PBST. Later, $100 \mu \mathrm{L}$ of streptavidin-HRP was added to each well and plates were incubated for 30 minutes at room temperature. Plates were again washed thrice with PBST and finally developed with tetramethylbenzidine. The absorbance was read at $450 \mathrm{~nm}$ with a microtiter plate reader. Titration curves of recombinant cytokines were used as standard for calculating cytokine concentrations in the samples tested.

\section{Staining of T cells for memory and macrophages for co-stimulatory markers}

Splenocytes belonging to various immunized groups were harvested as described earlier for the proliferation assay. $\mathrm{T}$ cells $\left(\mathrm{CD}^{+}\right.$and $\left.\mathrm{CD}^{+}\right)$were prepared for staining with labelled antibodies as described elsewhere. ${ }^{13}$ Viable cells were counted using the Trypan blue dye exclusion method. The fluorescence-activated cell sorting (FACS) express plus analysis demonstrated that isolated cells were CD4+ with $97 \%$ purity while the $\mathrm{CD}^{+}$population was found to be $98 \%$ pure. ${ }^{13}$ Further, $1 \times 10^{6} \mathrm{CD}^{+}$and $\mathrm{CD} 8^{+}$cells were washed twice in FACS buffer (PBS with $1 \%$ BSA and $0.1 \%$ sodium azide) in different tubes. We isolated the macrophages by adherence on petri-plates which were then washed three times with HBSS and incubated at $37^{\circ} \mathrm{C} .^{13}$ Moreover, we determined F4-80 expression on cells before assessing the expression level of costimulatory molecules in order to ascertain macrophage lineage of this population. Various isolated immune cells were incubated with Fc block (2.4G2) and fluorescein isothiocyanate/phycoerythrin (FITC/PE) tagged monoclonal antibodies (CD44, CD62L, CD80, CD86, and isotype control) for 30 minutes at $4^{\circ} \mathrm{C}$. After the appropriate washing steps, cells were fixed with $1.0 \%$ paraformaldehyde. The cytometry data were acquired using fluorescence activated cell sorter (GUAVA, Billerica, MA) and were analyzed with Express-Plus software (DME MAC Express Plus, National Government Services Common Electronic Data Interchange (CEDI), NHIC Corp, Hingham, MA). The total number of cells of a definite phenotype $\left(\mathrm{CD} 4{ }^{+} \mathrm{CD} 44^{\text {high }} \mathrm{CD} 62 \mathrm{~L}^{\text {high/low }}\right.$, $\mathrm{CD} 8{ }^{+} \mathrm{CD} 44^{\text {high }} \mathrm{CD} 62 \mathrm{~L}^{\text {high/low }}$ ) was calculated by taking the percentage of a gated cell type, as determined by flow cytometry, and multiplying it by the total number of cells obtained per sample, which was further divided by $100{ }^{16}$

\section{Ethics statement}

All animal experiments were approved by the Institutional Animal Ethics Committees of the Interdisciplinary Biotechnology Unit, Aligarh Muslim University, Aligarh, India. All animal experiments were performed according to the National Regulatory Guidelines issued by the Committee for the Purpose of Control and Supervision of Experiments on Animals (CPCSEA). Our approval ID is 332/CPCSEA, Ministry of Environment and Forests, Paryavaran Bhavan, Government of India.

\section{Prophylactic study}

To evaluate the protective efficacy of in-house prepared vaccine candidate, we challenged $\mathrm{BALB} / \mathrm{c}$ mice belonging to various vaccinated groups with $1 \times 10^{7} \mathrm{CFU}$ per animal at 4 weeks, and enumerated liver and spleen bacterial loads at various time points. For this, three animals from each group were sacrificed 1 week and 4 weeks post-challenge and their organs were crushed in PBS aseptically. Dilutions were plated onto BHI plates and after 48 hours of plating, the colonies were counted to calculate the bacterial load in various vital organs. Moreover, after the challenge, we observed the survival of animals belonging to various immunized groups and controls.

\section{Statistical analysis}

Data were analyzed and two groups were compared using Student's $t$-test and one-way ANOVA (Holm-Sidak method) was used to compare all groups to each other. SigmaPlot software (v 10 and 11; SigmaPlot, San Jose, CA) was used. $P$ values $<0.05(*),<0.01(* *)$, and $<0.001(* * *)$ were considered significant.

\section{Results SDS-PAGE and Western blot analysis of culture supernatant antigens}

Figure 1A shows the electrophoretic pattern of total proteins present in the culture supernatant of L. monocytogenes as seen 


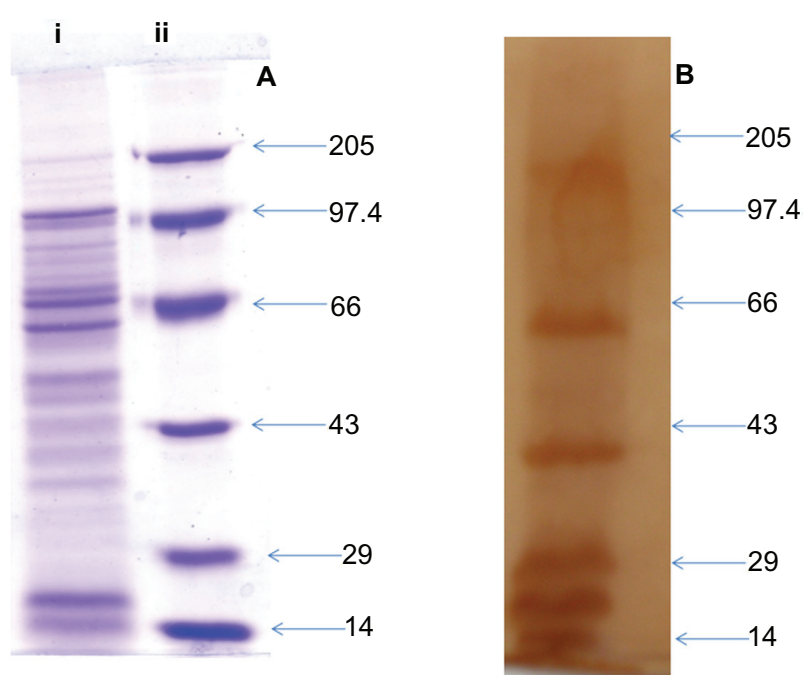

Figure I SDS-PAGE and Western blot profile of culture supernatant SAgs of Listeria monocytogenes. (A) SDS-PAGE profile of proteins present in L. monocytogenes culture supernatant. Lane $\mathbf{i}$ corresponds to protein profile and lane ii shows the molecular weight markers. (B) Western blot profile of the same proteins isolated from culture supernatant, probed with mouse antisera.

Abbreviations: SAgs, secretory protein antigens; SDS-PAGE, sodium dodecyl sulfate polyacrylamide gel electrophoresis.

by Coomassie Brilliant Blue staining. SDS-PAGE revealed prominent protein bands around $97 \mathrm{kD}, 60 \mathrm{kD}, 39 \mathrm{kD}$ and many bands in the size range of $29-14 \mathrm{kD}$, which is in concordance with earlier reports. ${ }^{12-17}$ The immunogenicity in terms of antigen-specific antibody production was assessed by Western blot analysis. The sera was found to recognize most of the SAgs, however, proteins corresponding to $110 \mathrm{kD}, 60$ $\mathrm{kD}, 39 \mathrm{kD}, 29 \mathrm{kD}, 18 \mathrm{kD}$, and $14 \mathrm{kD}$ were more immunogenic when compared to other SAgs, as elucidated by Figure 1B.

\section{Characterization of archaeosomes}

The size range of SAgs-bearing archaeosomes was characterized by using a nanophox analyzer, which showed an average size of $99.15 \pm 15 \mathrm{~nm}$ (Figure 2A). The SEM image further confirmed their size $(100 \mathrm{~nm})$ (Figure 2B). The interaction of calcein loaded archaeosomes with J774A.1 macrophages is demonstrated by confocal microscopy. All the archaeosomes in the solution were found to be accumulated efficiently, so that the entrapped calcein was completely delivered to the macrophages within 10 minutes - this shows that archaeosomal uptake by macrophages is prompt and efficient (Figure 2C).

\section{Archaeosome-encapsulated SAgs elicit elevated $\mathrm{Th} I$ response}

The effect of archaeosome-encapsulated SAgs on the induction of both Th1 (IFN- $\gamma$ and IL-12) and Th2 (IL-4) type cytokines was assessed in immunized animals at various time points both prior to and post-challenge with L. monocytogenes infection. Significantly high levels of Th1 cytokines; IFN- $\gamma$, and IL-12, were induced upon administration of archaeosome-entrapped SAgs when compared to the free form of SAgs $(P<0.001)$ and the physical mixture of archaeosomes with SAgs $(P<0.001)$, both at post-booster and post-challenge time points. However, the expression of Th1 cytokines was found to be higher post-challenge in archaeosome-entrapped SAgs-immunized group. Control groups showed low production of Th1 cytokines (Figure 3A and B). On the contrary, as depicted by Figure $3 \mathrm{C}$, archaeosome-based vaccine formulation induced significantly lower expression of Th2 cytokine and IL-4, when compared to the free form of SAgs $(P<0.001)$. The control groups failed to induce detectable levels of IL-4 at various post-booster time points, while the response at post-challenge showed comparable expression with that of SAgs-supplemented groups at various time points.

The antibody response against SAgs entrapped in archaeosomes was analyzed at various time points. The results shown in Figure 1 clearly reveal significant antibody levels after immunization with archaeosome-based antigens. The antibody responses were heightened at post-challenge time points for archaeosomal preparation, while a slight reduction was observed in other groups (Figure 3D).

Interestingly, the $\operatorname{IgG} 2 \mathrm{a} / \mathrm{IgG} 1$ ratio post-booster was significantly higher in the animals that were immunized with archaeosome-encapsulated SAgs when compared to their free form. The IgG2a induction was considerably enhanced in the group that was immunized with archaeosome-encapsulated SAgs at 2 weeks post-challenge with infection. On the other hand, there was a remarkable shift in antibody isotype induction in favor of IgG1 in the group that was immunized with the free form of SAgs post-challenge with infection (Figure 3D).

\section{Lymphocyte proliferative response}

Lymphocyte proliferation in response to immunization with archaeosome-based SAgs was used as a parameter to assess vaccine potential of SAgs-bearing archaeosomes. Lymphocytes obtained at various time points, post-booster as well as post-challenge, from the spleens of mice immunized with different SAgs vaccines proliferated upon their exposure to SAgs in a dose-dependent manner (Figure 4A). The proliferative response of lymphocytes obtained from animals immunized with archaeosome-entrapped antigens was significantly higher when compared to free SAgs $(P<0.001)$ and its physical mixture with archaeosome 



Figure 2 Characterization of archaeosomes and their interaction with macrophages. (A) Size of in-house prepared archaeosomes as determined by nanophox size analyzer (B) SEM image of archaeosomes and (C) interaction of archaeosomes with J774A.I macrophages as visualized by confocal microscopy. The left panel shows a fluorescence microscopic image of archaeosomes entrapped in macrophages, a bright field image of the same is shown in the middle panel and the right panel represents superpositioning of left and middle panels.

Abbreviation: SEM, scanning electron microscope.

at all time points $(P<0.001)$. The lymphocytes isolated from animals immunized with PBS and sham archaeosome (no antigen) failed to proliferate at any dose of SAgs. Graph plots (Figure 4B) reveal the lymphocyte proliferative response at a fixed dose of SAgs $(20 \mu \mathrm{g})$ at two different time points, viz, post-booster and post-challenge with infection. Among various forms of SAgs, archaeosome-encapsulated SAgs maintained a higher proliferative response at various time points (post-booster as well as post-challenge), when compared to the free form of SAgs or their physical mixture 

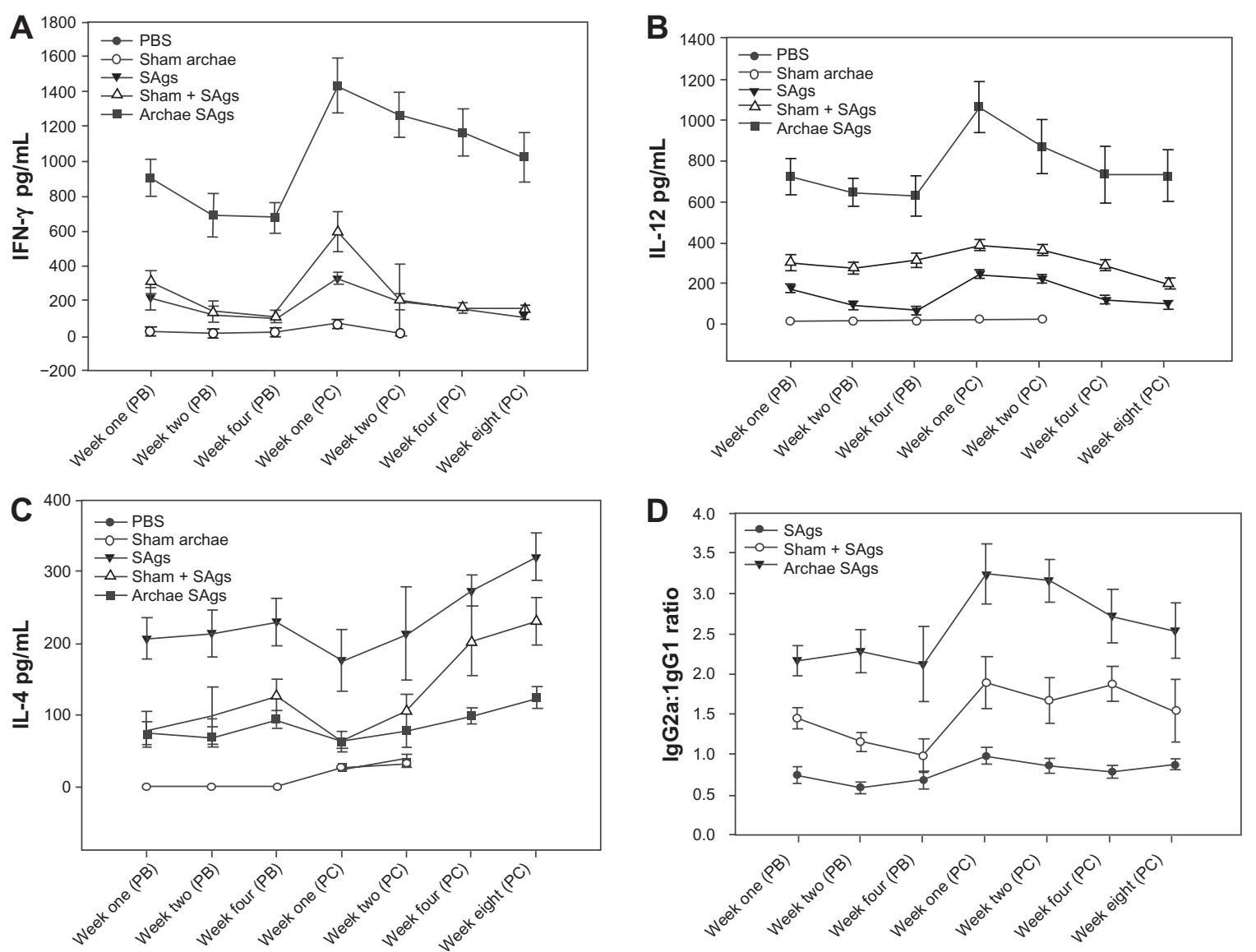

Figure 3 Archaeosome-entrapped SAgs induce ThI biased response in immunized mice. By determining cytokine response in splenocyte culture supernatant of various immunized groups, ThI/Th2 response was ascertained at different time points, prior and post-challenge with Listeria monocytogenes infection; (A) IFN- $\gamma$, (B) IL-I2, (C) IL-4. (D) Ratio of lgG2a to lgGI was analyzed in sera of various immunized groups except controls (PBS and sham archaeosomes) to further confirm THI/Th2 polarization upon immunization with archaeosome-entrapped SAgs.

Notes: The data represent the mean of three determinants \pm SD and are representative of three different experiments (ie, the experiment was done in triplicate) with similar observations. Statistically groups were compared with each other using ANOVA with the Holm-Sidak test (all pairwise multiple comparison procedures) with $P<0.05, P<0.01$, $P<0.00$ I, post-booster, and post-challenge.

Abbreviations: PBS, phosphate buffer saline; SD standard deviation; ANOVA, analysis of variance; SAgs, secretory protein antigens.
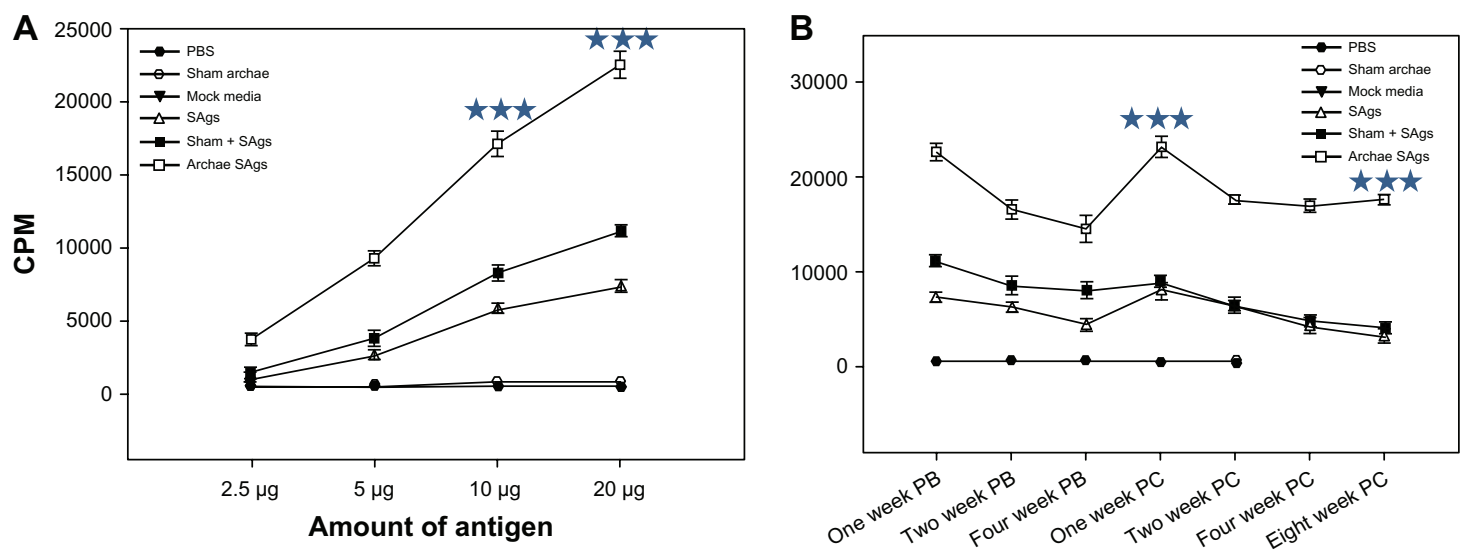

Figure 4 Proliferative response of lymphocytes belonging to various immunized groups upon stimulation with SAgs. To determine the effect of the amount of SAgs on the proliferation of lymphocytes, lymphocytes isolated from the spleens of immunized BALB/c mice of various vaccinated groups including controls, were cultured in flat-bottomed 96-well plates. The cells were co-cultured in the presence of increasing doses (I-20 $\mu \mathrm{g})$ of corresponding formulations of SAgs as well as controls. After 72 hours $\left[{ }^{3} \mathrm{H}\right]-$ thymidine was added and its incorporation into multiplying cells was measured after 16 hours of incubation, using liquid scintillation spectroscopy. The CPM values of stimulated culture were used to represent Ag-specific stimulation. (A) Dose-dependent proliferative response of lymphocytes at I-week post-booster and post-challenge (data not shown) upon stimulation with various SAgs formulations. (B) Lymphocyte proliferation in terms of CPM values in various immunized groups at PB and 2 weeks PC time points.

Notes: Data represent the mean of three determinants \pm SD. The figures are representative of three independent experiments. The groups were compared using ANOVA. Holm-Sidak test (all pairwise multiple comparison procedures) with $* * * P<0.001$.

Abbreviations: CPM, counting per minute; PB, post-booster; PC, post-challenge; PBS, phosphate buffer saline; ANOVA, analysis of variance; SD, standard deviation; SAgs, secretory protein antigens. 
with sham archaeosomes. However, post-challenge, the proliferative response of lymphocytes belonging to either group (physical mixture and free form) was found to be more or less similar $(P=0.170)$.

\section{Archaeosome-encapsulated SAgs evoke delayed type hypersensitivity in immunized animals}

To evaluate the ability of various forms of SAgs to induce cell-mediated immune response, we immunized mice subcutaneously (SC) in the lower abdominal region. Free SAgs were used as immunogen to determine whether they need an adjuvant for evoking desirable immune response. Seven days after immunization, mice were exposed to SAgs or PBS via the footpad and footpad swelling was measured at various time intervals. Immunization with SAgs entrapped in archaeosomes resulted in the generation of a strong DTH response whereas the physical mixture of SAgs and sham archaeosomes resulted in a moderate DTH response. Antigens in free form induced minimal anti-listerial DTH response (Figure 5). However, sham archaeosome as well as PBS-immunized mice showed negligible DTH response.

\section{Archaeosome-encapsulated SAgs upregulate costimulatory molecule expression}

We also analyzed the expression profile of costimulatory markers on macrophages isolated from various immunized groups using flow cytometry. As shown in Figure 6, higher expression of CD80 (B7-1) and CD86 (B7-2) was observed in the group immunized with archaeosome-entrapped SAgs (CD80 49.74\% \pm 4.87\%; CD86 47.86\% \pm 5.34\%) when compared to free form of SAgs and their physical mixture with sham archaeosomes, on the fourth week post-challenge $(P<0.001)$. A similar expression profile of costimulatory molecules was observed on macrophages isolated from free SAgs and physical mixture immunized groups. The histograms (Figure 6A and B) clearly show the difference between the concerned groups, the groups immunized with sham archaeosomes were considered as the control, while Figure 6C and D depict the mean value of the percentage population of CD80 and CD86, respectively. Data here in the form of the bar graph are representative of three different experiments.

\section{Archaeosome-entrapped SAgs elicit a strong memory response in immunized mice}

In order to evaluate the ability of archaeosome-based vaccine to induce desirable memory response in $\mathrm{CD}^{+}$and $\mathrm{CD}^{+} \mathrm{T}$ cells against $L$. monocytogenes, we enumerated the population having $\mathrm{CD} 44^{\text {high }} \mathrm{CD} 62 \mathrm{~L}^{\text {high }}$ for central memory and $\mathrm{CD} 44^{\text {high }} \mathrm{CD} 62 \mathrm{~L}^{\text {low }}$ for effector memory marker on their surface and presented it in the form of a dot plot (Figure 7A and B). The bar graphs clearly show the presence of $\mathrm{CD} 44^{\text {high }} \mathrm{CD} 62 \mathrm{~L}^{\text {low/high }}$ on the surface of both CD4

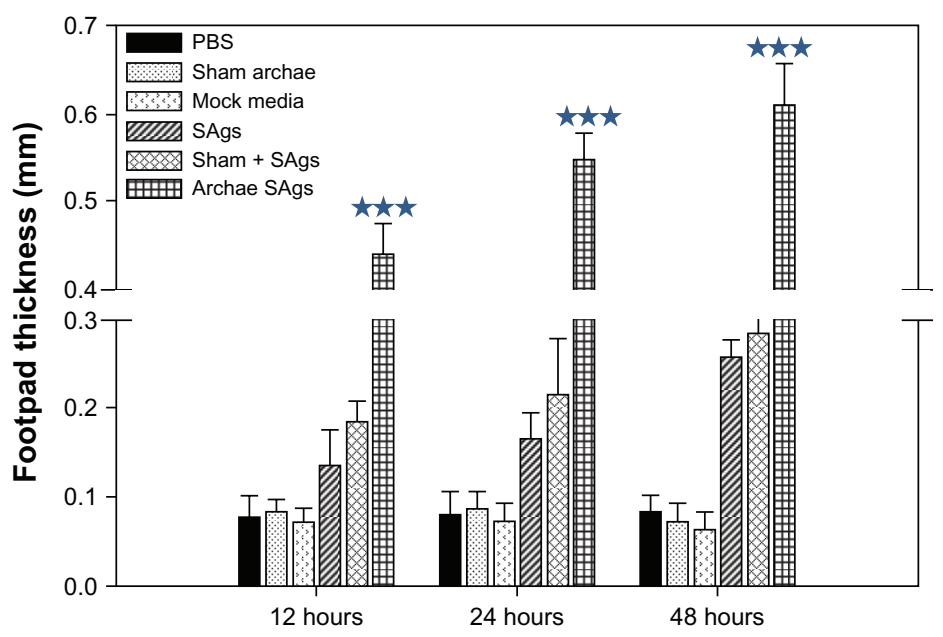

Figure 5 Archaeosome-entrapped SAgs generate strong DTH response. To ascertain the induction ability of archaeosome-entrapped SAgs to evoke cell-mediated immune response in the immunized mice, mean DTH response was evaluated by measuring footpad swelling in the groups immunized with PBS, sham archaeosomes, free SAgs, sham archaeosomes mixed with free SAgs, and archaeosomes-entrapped SAgs (Archae-SAgs) after various time intervals; DTH response was found to be substantially high in the group immunized with archaeosome-encapsulated SAgs.

Notes: Data are representative of three independent experiments \pm SD values. ***P values $<0.00$ I were considered statistically significant. Archaeosome-entrapped SAgs vs free SAgs ****P $<0.001$.

Abbreviations: PBS, phosphate buffer saline; SD, standard deviation; DTH, delayed type hypersensitivity; SAgs, secretory protein antigens. 
A


B



CD-86
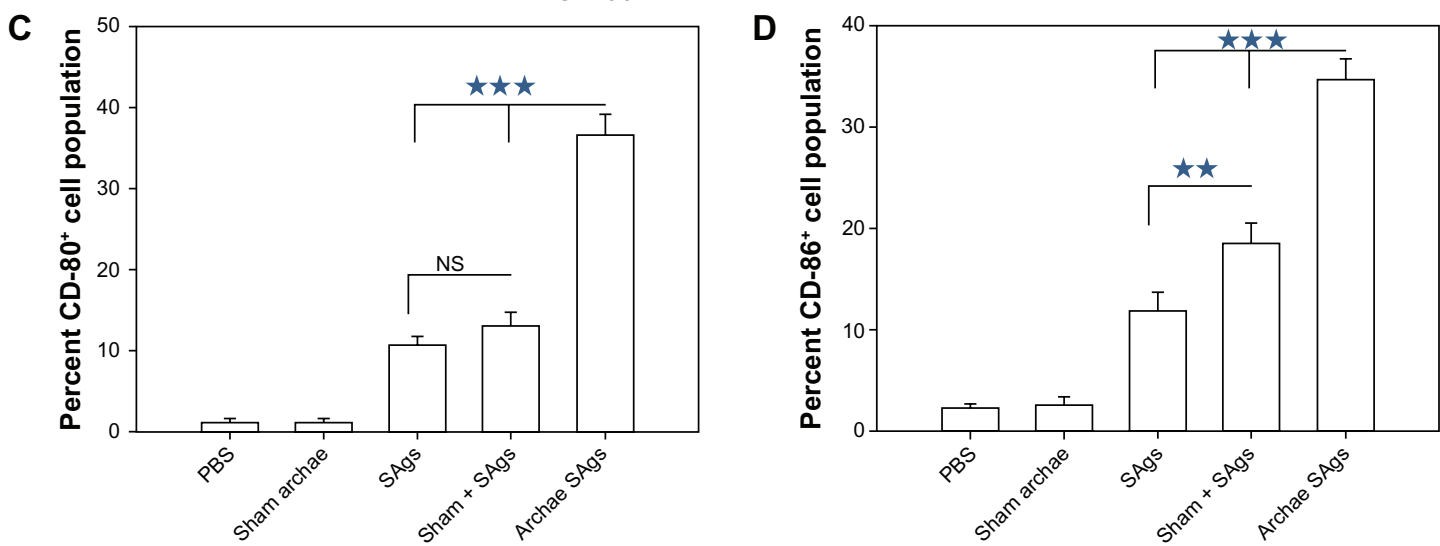

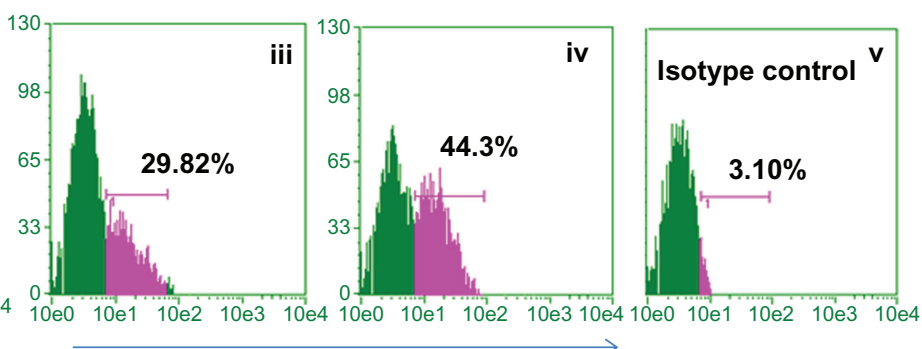

Figure 6 Archaeosome-entrapped SAgs upregulate the expression of costimulatory molecules on antigen-presenting cells. The expression of costimulatory molecules, CD80 (B7-I) and CD86 (B7-2), on macrophages was determined by staining target cells with specific antibodies and subsequent analysis by flow cytometry at 2 weeks post-challenge. The dot plot graphs for (A) CD80 and (B) CD86 represent various immunized groups: (i) Sham archaeosomes as control; (ii) free culture supernatant SAgs; (iii) Sham + SAgs as a physical mixture; (iv) Archaeosome-entrapped culture supernatant SAgs and (v) and isotype control. The bar graphs corresponding to (C) CD80 and (D) CD86 depict the mean percentage of three determinants ( $\pm S D)$.

Notes: Data were analyzed with Student's $t$-test and are representative of three independent experiments. Archaeosome-entrapped SAgs vs free SAgs $* * * P<0.00$ I (CD80), *** $P<0.00$ I (CD86); physical mixture vs free SAgs $P=$ NS (CD80), **P $<0.01$. The CD80/86 population histogram was same as that of sham archaeosome and is not shown.

Abbreviations: PBS, phosphate buffer saline; SD, standard deviation; SAgs, secretory protein antigens; NS, not significant.

and CD8 positive cells isolated from animals immunized with various forms of SAgs (Figure 7C and D). The animals immunized with the physical mixture and free SAgs showed nearly similar $\mathrm{CD} 4{ }^{+} \mathrm{CD} 44^{\text {high }} \mathrm{CD} 62 \mathrm{~L}^{\text {high }}$ (central memory) populations. On the other hand, when immunized with archaeosome-entrapped SAgs, a significantly higher central memory population was seen in the immunized animals (Archae SAgs vs Sham + SAgs $P<0.001$, Archae SAgs vs SAgs $P<0.001)$. A similar pattern was obtained when the memory cell population was enumerated in $\mathrm{CD} 8^{+} \mathrm{T}$ cells, the group immunized with archaeosome-entrapped SAgs showed a higher central memory population both compared to free SAgs $(P<0.001)$ and with the physical mixture $(P<0.001)$. Moreover, only the animals immunized with archaeosome-entrapped SAgs showed $\mathrm{CD} 44^{\text {high }} \mathrm{CD} 62 \mathrm{~L}^{\text {low }}$ (effector memory) populations in both $\mathrm{CD}^{+}$and $\mathrm{CD} 8^{+}$ $\mathrm{T}$ cells. The results clearly reveal that both central memory as well as effector memory cell population (in both $\mathrm{CD} 4^{+}$ and $\mathrm{CD} 8^{+} \mathrm{T}$ cells) persist significantly when animals are immunized with archaeosome-entrapped SAgs.

\section{Archaeosome-based SAgs impart better protection against $L$. monocytogenes infection}

The efficacy of archaeosome-encapsulated SAgs was evaluated against experimental murine listeriosis in BALB/c mice at various time points post-challenge with infection by determining residual bacterial burden in their vital organs. 




B

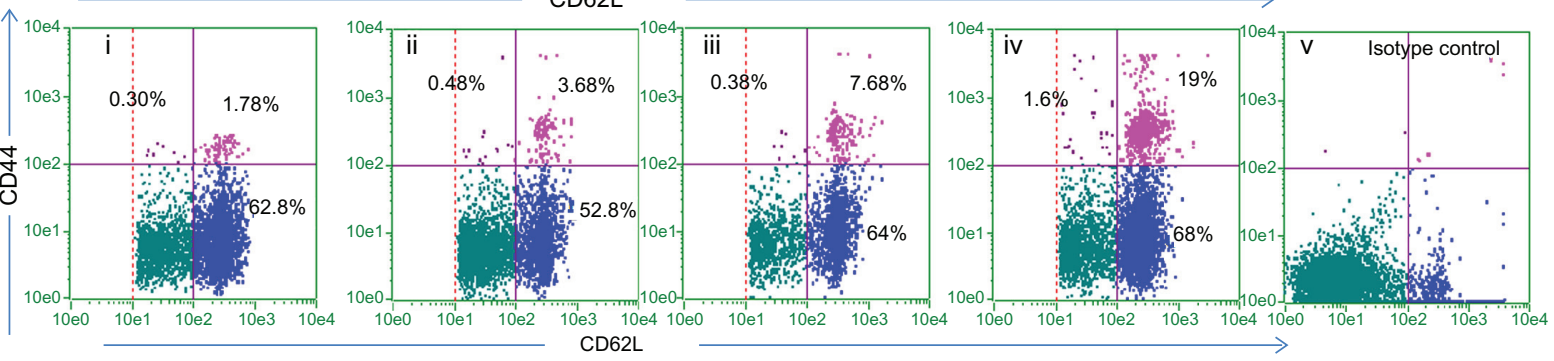

C
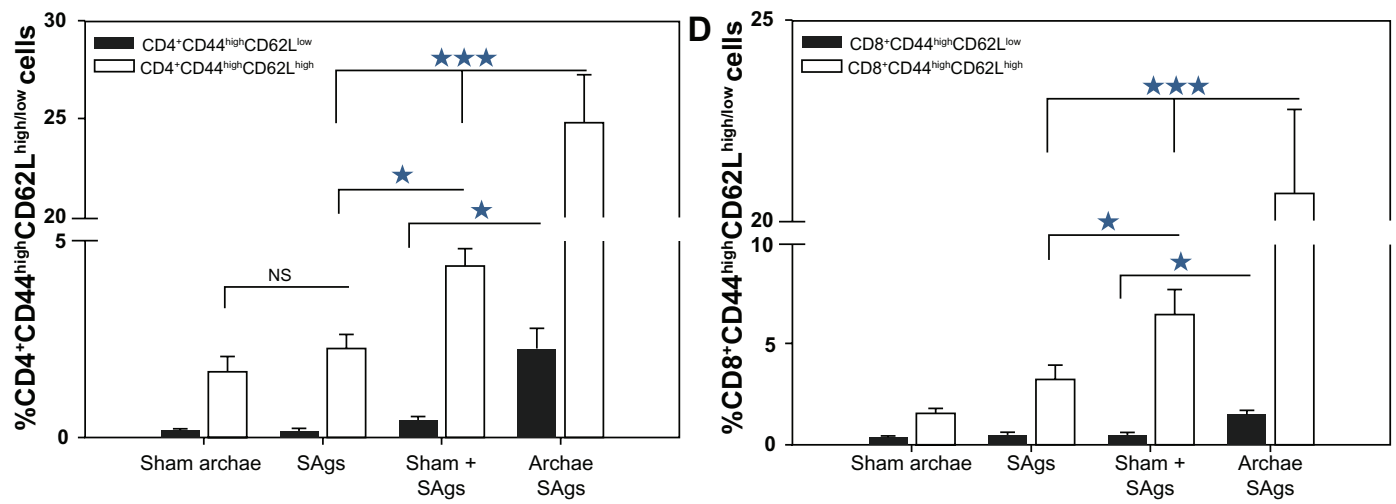

Figure 7 Augmentation of $\mathrm{CD}^{+} / \mathrm{CD} 4^{+} \mathrm{T}$ cell effector memory response upon immunization with archaeosome-entrapped SAgs. The CD4 ${ }^{+}$and $\mathrm{CD} 8^{+} \mathrm{T}$ cells were harvested and their purity was depicted as described in the 'Materials and methods' section. The $(\mathbf{A}) \mathrm{CD} 4^{+} \mathrm{CD} 44^{\text {high }} \mathrm{CD} 62 \mathrm{~L}^{\text {low/high }}$ and $(\mathbf{B}) \mathrm{CD} 8^{+} \mathrm{CD} 44^{\text {high }} \mathrm{CD} 62 \mathrm{~L}^{\text {low/high }}$ phenotypes were analyzed using flow cytometry at 2 weeks post-challenge, representing various immunized groups: (i) Sham archaeosomes as control; (ii) free culture supernatant SAgs; (iii) Sham + SAgs as aphysical mixture; (iv) archaeosome-entrapped culture supernatant SAgs; and (v) isotype control. The bar graph depicts the population of (C) $C D 44^{+} C D 44^{\text {high }} \mathrm{CD} 62 \mathrm{~L}^{\text {highllow }}$ and (D) $\mathrm{CD} 8^{+} \mathrm{CD} 44^{\text {high }} \mathrm{CD} 62 \mathrm{~L}^{\text {highllow }}$ and is representative of three independent experiments and presented as mean $\pm \mathrm{SD}$.

Notes: Archaeosome-entrappedSAgs vs free SAgs ***P $<0.001$ (CD4 $\left.{ }^{+} C D 44^{\text {high }} C D 62 L^{\text {high }} ; C D 44^{+} C D 44^{\text {high }} C D 62 L^{\text {low }}\right), P<0.001$ ( $C D 8^{+} C D 44^{\text {high }} C D 62 L^{\text {high }} ; C D 88^{+} C D 44^{\text {high }} C D 62 L^{\text {low }}$ ); physical mixture vs free SAgs $* P<0.05 C D 44^{+} C D 44^{\text {high }} C D 62 L^{\text {high }} ; P=N S C D 4{ }^{+} C D 44^{\text {high }} C D 62 L^{\text {low }}, P<0.05 C D 8{ }^{+} C D 44^{\text {high }} C D 62 L^{\text {high }} ; P=N S C D 8{ }^{+} C D 44^{\text {high }} C D 62 L^{\text {low }}$.

Abbreviations: SD, standard deviation; SAgs, secretory protein antigens; NS, not significant.

The animals were immunized with various forms of SAgs and subsequently challenged intraperitoneally with $1 \times 10^{7}$ cells of L. monocytogenes. The animals immunized with archaeosome-based SAgs showed $2.533 \log _{10}$ reduction in the bacterial load of their livers when compared to PBS $(P<0.001)$ at 1 -week post-challenge with infection. The free form of SAgs on the other hand offered $1.36 \log _{10}$ reduction when compared to the PBS group $(P<0.001)$. It is noteworthy that the archeosome-SAgs formulation further depleted bacterial burden to significantly lower levels at 4 weeks postinfection, while other formulations did not maintain their effectiveness and resulted in an increase of bacterial load in various vital organs. Animals belonging to the PBS control and sham archaeosome groups died before 4 weeks postinfection and could not be included in the study (Figure 8A). The prophylactic potential of SAgs-archaeosomes was further confirmed by assessing the bacterial load in the spleen of immunized animals. Among various forms of SAgs, only the archaeosome SAgs-based formulation was effective in eliminating bacterial burden from the spleen of immunized animals $(P<0.001)$ (Figure 8B).

For survival studies, animals were challenged with $1 \times 10^{7}$ cells/animal. The dose was found to be effective in establishing full blown infection as control animals (given only PBS) succumbed to death by 20 days post-challenge. Animals immunized with archaeosome-encapsulated SAgs exhibited $80 \%$ survival on day 15 post-infection while $70 \%$ of the animals survived in the group that was immunized with free SAgs and their physical mixture with sham archaeosomes. On day 30 post-challenge, around 70\% survival was seen in the archaeosome-entrapped SAgs group while there was $40 \%$ survival of the animals immunized with free SAgs and 

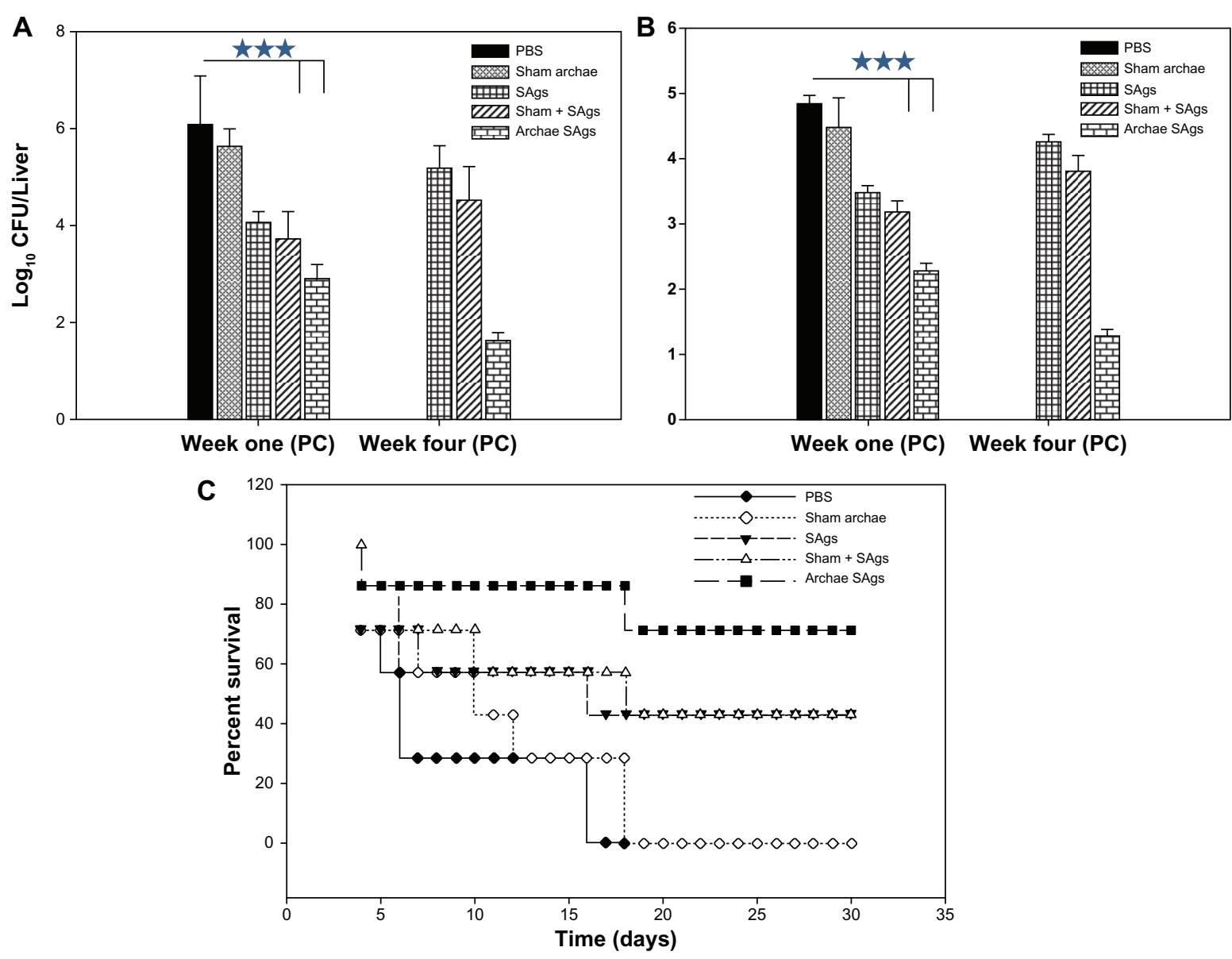

Figure 8 Archaeosome-encapsulated SAgs exhibit better protective effect against L. monocytogenes challenge in BALB/c mice. The bacterial load in the (A) liver and (B) spleen of vaccinated mice belonging to various groups was enumerated by plating their liver and spleen homogenates and counting the numbers of CFUs at I and 4 weeks post-challenge. The animals from various vaccinated groups were challenged with $\mathrm{I} \times 10^{7} \mathrm{CFU}$, thereafter they were monitored for a period of $\mathrm{I}$ month. (C) Data are represented here in terms of percentage survival.

Notes: The data are expressed as means of three determinants \pm SD and are representative of three independent experiments. Statistical analysis was performed by analysis of variance with the Holm-Sidak method (all pairwise multiple comparison procedures) to compare the significance between the two groups. $* * * P<0.00 I$ value was considered significant.

Abbreviations: CFU, colony-forming unit; SAgs, secretory protein antigens; PBS, phosphate buffer saline; SD standard deviation.

the physical mixture of SAgs with sham archaeosomes. As shown in Figure 8, no animal survived in the group treated with sham archaeosomes and the PBS control group beyond day 17 post-infection (Figure 8C).

\section{Discussion}

L. monocytogenes has been implicated as the causative agent in several outbreaks of foodborne infections in the past few years. Besides pregnant women and their fetuses, immunocompromised subjects are also liable to Listeria infection. Several strategies have been attempted employing heat-inactivated, ${ }^{18,19}$ formalin-killed ${ }^{20}$ and heat-killed bacteria supplemented with Lysteriolysin-O (a potent Listeria antigen $)^{21}$ as a protection strategy against $L$. monocytogenes challenge but unfortunately with little success. This clearly shows the inefficacy of existing vaccines and warrants further research that could result in the development of novel prophylactic strategies to combat listerial infection. Earlier, Sprott et $\mathrm{al}^{9}$ demonstrated the potential of archaeosomes in evoking a desirable immune response in the host against a model antigen. Using the same approach in the current study, we evaluated the potential of an archaeosome-based delivery system against the model disease listeriosis. We speculate that archaeosome-entrapped SAgs can activate immune cells, owing to the immunoadjuvant property of archaeosomes, thereby offering prophylactic and protective immune responses. ${ }^{22,23}$

Archaeosomes are potential adjuvants capable of promoting strong humoral, ${ }^{9,24}$ cell-mediated (Th1), ${ }^{24}$ and cytotoxic $\mathrm{T}$ cell responses against entrapped protein antigens. ${ }^{25}$ While the physical association of the protein antigens with archael lipids seems to be important for the induction of a 
strong humoral response, it is, however, encapsulation in archaeosomes that is mandatory to induce a strong $\mathrm{CD}^{+}$ $\mathrm{T}$ cell memory response in the immunized host. ${ }^{26}$

The purpose of the present study was to ascertain the efficacy of archaeosome-encapsulated SAgs in terms of the induction of immunological memory and prophylactic responses against L. monocytogenes. To evaluate memory and prophylactic responses, mice from various immunized groups were challenged 8 weeks post last booster. Archaeosome-entrapped SAgs formulation was found to successfully generate long-lasting memory and costimulatory markers on active immune cells. As far as prophylactic response was concerned, although free SAgs and physical mixture of antigens with sham archaeosomes did induce IFN- $\gamma$ and IL-12 cytokines substantially, archaeosomeentrapped SAgs in addition to robust production of Th1 cytokines also suppressed the level of Th2 cytokines, indicating Th1 biased response (Figure 3).

To further validate the Th1 skewed response of archaeosome-based SAgs formulation, we determined isotypes of the Ag-specific antibody in the sera of various immunized groups. It has been reported that when B cells interact with Th1 cells, they mainly produce IgG2a, whereas their interaction with Th2 cells mainly leads to secretion of IgG1 ${ }^{27}$ A higher content of IgG2a-type antibodies in the sera of animals immunized with archaeosome-entrapped SAgs further supports our notion that SAgs-bearing archaeosomes are biased for the induction of Th1 cytokines. IFN- $\gamma$, a Th1 cytokine, induces antibody switching with IgG2a isotype by B cells. ${ }^{27}$ Besides, IFN- $\gamma$ also upregulates LMP-2, LMP-7, and TAP-1/TAP-2 genes that facilitate processing of antigen via class I pathway.

Lymphocyte proliferation assay revealed enormous proliferation of SAgs-specific T lymphocytes, suggesting adjuvant potential of archaeosome-encapsulated antigen. However, considerably lesser lymphoproliferative activity was observed with the free form of SAgs when compared to the group immunized with their physical mixture with sham archaeosomes (Figure 4B). Delayed type hypersensitivity response, another important parameter to validate the potential of archaeosome-based vaccines, was found to be two to three times more pronounced than free SAgs and the physical mixture (Figure 5). In general, the free form of antigens are incapable of producing cytotoxic $\mathrm{T}$ cell immune response due to their inability to undergo class I processing, which is a limitation of subunit vaccines, preventing their implementation in vaccination programs. ${ }^{28}$ Thus, one can anticipate that increasing the particulate nature and promot- ing the delivery of the subunit antigen to APCs would likely enhance its immunogenicity.

APCs (macrophages, DCs) bearing CD80 (B7-1) and CD86 (B7-2) costimulatory molecules facilitate $\mathrm{T}$ cell activation, by harnessing CD28 on T cells for signaling. ${ }^{29}$ We enumerated the percentage population of costimulatory surface molecule bearing macrophages belonging to various immunized groups. The data of the present study show maximum costimulation by archaeosome-entrapped SAgs when compared to free SAgs, or physical mixture of SAgs with sham archaeosome groups $(P<0.001)$. CD44, an adhesion molecule, is expressed by most cells and mediates binding to the extracellular matrix and other cells via its only known in vivo ligand, the glycosaminoglycan hyaluronic acid (HA). ${ }^{30}$ Enormous upregulation of CD44 on both $\mathrm{CD}^{+}$and $\mathrm{CD} 8^{+}$ $\mathrm{T}$ cell population was observed in the animals immunized with archaeosome-entrapped SAgs even after 16 weeks of immunization, indicating the induction of a heightened memory response, as CD44 ${ }^{\text {high }}$ cells are classically associated with the memory phenotype. ${ }^{31}$ Memory was further divided into two major populations on the basis of CD62L marker, ie, CD 44 ${ }^{\text {high }} \mathrm{CD} 62 \mathrm{~L}^{\text {high }}$ (central memory) and CD 44 ${ }^{\text {high }} \mathrm{CD} 62 \mathrm{~L}^{\text {low }}$ (effector memory). In general, central memory persists after rapid clearance of acute infections, and is more effective in controlling secondary infections involving intracellular pathogens. ${ }^{32}$ On the other hand, the effector memory was reported to be induced by chronic infections. ${ }^{33,34}$ The animals immunized with archaeosome-entrapped SAgs showed higher populations of $\mathrm{CD} 44^{\text {high }} \mathrm{CD} 62 \mathrm{~L}^{\text {high/low }}$ (ie, both central as well as effector memory) than all other groups in CD4 ${ }^{+}$ and $\mathrm{CD}^{+} \mathrm{T}$ cells isolated from animals belonging to various immunized groups. This long-lasting memory could again be attributed to the good adjuvant potential of archaeosomes and their efficient interactive capability with APCs, especially macrophages. On the other hand, free SAgs and the physical mixture induced lower production of $\mathrm{CD} 44^{\text {high }} \mathrm{CD} 62 \mathrm{~L}^{\text {high }}$, on both CD4 and CD8 positive T cells, indicative of feeble memory response in these groups (Figure 7).

In murine models, within minutes after intravenous inoculation, most of the bacteria could be found in the spleen and liver. ${ }^{2}$ However, even after 4 weeks of challenge, relevant depletion of bacterial load was observed in the liver and spleen of mice vaccinated with archaeosome-entrapped SAgs (Figure 8A and B). Finally, protection studies showed remarkable survival rates in animals immunized with archaeosomeencapsulated SAgs in comparison with free SAgs and physical mixture groups; moreover, the control animals did not survive the 17th day post-infection (Figure 8C). 
The lipid vesicles prepared from total polar lipids of archaebacteria (H. salinarum), known as archaeosomes, serve not only as humoral adjuvant, but also induce a strong cytotoxic $\mathrm{T}$ cell response characterized by long-term memory, and are also nontoxic in comparison to Freund's adjuvant. ${ }^{11}$ They lead to elicitation of cytotoxic $T$ cell response by processing encapsulated antigen via cytosolic pathway followed by enhanced MHC1 presentation. ${ }^{22}$ The currently available antigen delivery systems like virosomes, $\mathrm{pH}$ sensitive liposomes, or fusogenic protein-bearing liposomes, though capable of inducing strong immune responses against entrapped antigen, suffer limitations like low cost effectiveness, instability, and toxicity. However, archaeosomes are believed to have overcome such hurdles and are also suggested to be more stable than the conventional ester lipid liposomes due to their potential to withstand air oxidation and acid/base mediated hydrolysis. ${ }^{11}$

\section{Conclusion}

Archaeosomes are found to efficiently deliver antigen to professional antigen presenting cells that ensued in provoking robust (Th1-biased) immunological response in model animals. Interestingly, the archaeosome-based Listeria SAgs vaccine was also found to meet criteria such as T-cell proliferation, up-regulation of co-stimulatory molecules, as well as both central and effector memory responses that are ought to be desirable for prophylaxis against intracellular pathogens. Consequently, we suggest that archaeosome-based delivery of culture supernatant antigens can be translated to develop a vaccine candidate for the obliteration of $L$. monocytogenes and other intracellular pathogens.

\section{Acknowledgments}

The authors express their gratitude to Professor MSaleemuddin, Coordinator IBU, Aligarh, for providing the facilities to complete this study. Mairaj Ahmed Ansari acknowledges the financial support of the Indian Council of Medical Research (ICMR) in the form of a fellowship.

\section{Disclosure}

The authors report no conflicts of interest in this work.

\section{References}

1. Hamon M, Bierne H, Cossart P. Listeria monocytogenes: a multifaceted model. Nat Rev Microbiol. 2006;4(6):423-434.

2. Freitag NE, Port GC, Miner MD. Listeria monocytogenes - from saprophyte to intracellular pathogen. Nat Rev Microbiol. 2009;7(9):623-628.

3. Gaillard JL, Berche P, Mounier J, Richard S, Sansonetti P. In vitro model of penetration and intracellular growth of Listeria monocytogenes in the humanenterocyte-like cell line Caco-2. Infect Immun. 1987; 55(11):2822-2829.
4. Bouwer HG, Nelson CS, Gibbins BL, Portnoy DA, Hinrichs DJ. Listeriolysin $\mathrm{O}$ is a target of the immune response to Listeria monocytogenes. J Exp Med. 1992;175(6):1467-1471.

5. Wood S, Maroushek N, Czuprynski CJ. Multiplication of Listeria monocytogenes in a murine hepatocyte cell line. Infect Immun. 1993; 61(7):3068-3072.

6. Drevets DA, Sawyer RT, Potter TA, Campbell PA. Listeria monocytogenes infects human endothelial cells by two distinct mechanisms. Infect Immun. 1995;63(11):4268-4276.

7. Dramsi S, Lévi S, Triller A, Cossart P. Entry of Listeria monocytogenes into neurons occurs by cell-to-cell spread: an in vitro study. Infect Immun. 1998;66(9):4461-4468.

8. Guzman CA, Rohde M, Chakraborty T, et al. Interaction of Listeria monocytogenes with mouse dendritic cells. Infect Immun. 1995;63(9): 3665-3673.

9. Sprott GD, Tolson DL, Patel GB. Archaeosomes as novel antigen delivery systems. FEMS Microbiol Lett. 1997;154(1):17-22.

10. Krishnan L, Sprott GD. Archaeosome adjuvants: immunological capabilities and mechanism(s) of action. Vaccine. 2008;26(17):2043-2055.

11. Patel GB, Omri A, Deschatelets L, Sprott GD. Safety of archaeosome adjuvants evaluated in a mouse model. J Liposome Res. 2002;12(4): 353-372.

12. Desvaux M, Hébraud M. The protein secretion systems in Listeria: inside out bacterial virulence. FEMS Microbiol Rev. 2006;30(5):774-805.

13. Mallick AI, Singha H, Khan S, et al. Escheriosome-mediated delivery of recombinant ribosomal L7/L12 protein confers protection against murine brucellosis. Vaccine. 2007;25(46):7873-7884.

14. Owais M, Gupta CM. Liposome-mediated cytosolic delivery of macromolecules and its possible use in vaccine development. Eur J Biochem. 2000;267(13):3946-3956.

15. Buchanan KL, Murphy JW. Characterization of cellular infiltrates and cytokine production during the expression phase of the anticryptococcal delayed-type hypersensitivity response. Infect Immun. 1993;61(7): 2854-2865.

16. Darrah PA, Patel DT, De Luca PM, et al. Multifunctional TH1 cells define a correlate of vaccine-mediated protection against Leishmania major. Nat Med. 2007;13(7):843-850.

17. Trost M, Wehmhöner D, Kärst U, Dieterich G, Wehland J, Jänsch L. Comparative proteome analysis of secretory proteins from pathogenic and nonpathogenic Listeria species. Proteomics. 2005;5(6): 1544-1557.

18. Miller MA, Skeen MJ, Ziegler HK. Protective immunity to Listeria monocytogenes elicited by immunization with heat-killed Listeria and IL-12. Potential mechanism of IL-12 adjuvanticity. Ann N Y Acad Sci. 1996;797:207-227.

19. Kursar M, Köhler A, Kaufmann SH, Mittrücker HW. Depletion of CD4+ $\mathrm{T}$ cells during immunization with nonviable Listeria monocytogenes causes enhanced $\mathrm{CD} 8^{+} \mathrm{T}$ cell-mediated protection against listeriosis. J Immunol. 2004;172(5):3167-3172.

20. Miller DC, Czuprynski CJ. Passive immunization with convalescent serum, or oral immunization with formalin-killed organisms, does not protect mice against gastrointestinal challenge with Listeria monocytogenes. Comp Immunol Microbiol Infect Dis. 2002;25(2):69-75.

21. Xiong H, Tanabe Y, Ohya S, Mitsuyama M. Administration of killed bacteria together with listeriolysin $\mathrm{O}$ induces protective immunity against Listeria monocytogenes in mice. Immunology. 1998;94(1):14-21.

22. Kates M, Deroo PW. Structure determination of the glycolipid sulfate from the extreme halophile Halobacterium cutirubrum. J Lipid Res. 1973;14(4):438-445.

23. Ekiel I, Marsh D, Smallbone BW, Kates M, Smith IC. The state of the lipids in the purple membrane of Halobacterium cutirubrum as seen by 31P NMR. Biochem Biophys Res Commun. 1981;100(1): $105-110$.

24. Krishnan L, Dicaire CJ, Patel GB, Sprott GD. Archaeosome vaccine adjuvants induce strong humoral, cell-mediated, and memory responses: comparison to conventional liposomes and alum. Infect Immun. 2000;68(1):54-63. 
25. Krishnan L, Sad S, Patel GB, Sprott GD. Archaeosomes induce longterm $\mathrm{CD}^{+}$cytotoxic $\mathrm{T}$ cell response to entrapped soluble protein by the exogenous cytosolic pathway, in the absence of $\mathrm{CD}^{+} \mathrm{T}$ cell help. J Immunol. 2000;165(9):5177-5185.

26. Krishnan L, Gurnani K, Dicaire CJ, et al. Rapid clonal expansion and prolonged maintenance of memory $\mathrm{CD} 8^{+} \mathrm{T}$ cells of the effector (CD44 ${ }^{\text {high }}$ CD62L ${ }^{\text {low }}$ ) and central $\left(\mathrm{CD} 44^{\text {high }} \mathrm{CD} 62 \mathrm{~L}^{\text {high }}\right.$ ) phenotype by an archaeosome adjuvant independent of TLR2. J Immunol. 2007; 178(4):2396-2406.

27. Agrewala JN, Wilkinson RJ. Differential regulation of Th1 and Th2 cells by p91-110 and p21-40 peptides of the 16-kD alpha-crystallin antigen of Mycobacterium tuberculosis. Clin Exp Immunol. 1998;114(3): 392-397.

28. Burnette WN. Recombinant subunit vaccines. Curr Opin Biotechnol. 1991;2(6):882-892.
29. Lenschow DJ, Walunas TL, Bluestone JA. CD28/B7 system of T cell costimulation. Annu Rev Immunol. 1996;14:233-258.

30. Ponta H, Sherman L, Herrlich PA. CD44: from adhesion molecules to signalling regulators. Nat Rev Mol Cell Biol. 2003;4(1):33-45.

31. Dutton RW, Bradley LM, Swain SL. T cell memory. Annu Rev Immunol. 1998;16:201-223.

32. Wherry EJ, Teichgräber V, Becker TC, et al. Lineage relationship and protective immunity of memory CD8 T cell subsets. Nat Immunol. 2003;4(3):225-234.

33. Appay V, Dunbar PR, Callan M, et al. Memory CD8 ${ }^{+} \mathrm{T}$ cells vary in differentiation phenotype in different persistent virus infections. Nat Med. 2002;8(4):379-385.

34. Champagne P, Ogg GS, King AS, et al. Skewed maturation of memory HIV-specific CD8 T lymphocytes. Nature. 2001;410(6824):106-111.
International Journal of Nanomedicine

\section{Publish your work in this journal}

The International Journal of Nanomedicine is an international, peerreviewed journal focusing on the application of nanotechnology in diagnostics, therapeutics, and drug delivery systems throughout the biomedical field. This journal is indexed on PubMed Central,

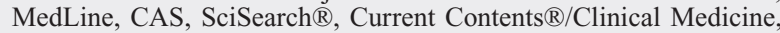

\section{Dovepress}

Journal Citation Reports/Science Edition, EMBase, Scopus and the Elsevier Bibliographic databases. The manuscript management system is completely online and includes a very quick and fair peer-review system, which is all easy to use. Visit http://www.dovepress.com/ testimonials.php to read real quotes from published authors.

Submit your manuscript here: http://www.dovepress.com/international-journal-of-nanomedicine-journal 